\title{
UMA ANÁLISE DA INSTRUÇÃO NORMATIVA N. 95 DO INPI À LUZ DA TEORIA DA IGUALDADE DE RECURSOS DE RONALD DWORKIN: as indicações geográficas e as comunidades tradicionais
}

\author{
Suzy Elizabeth Cavalcante Koury ${ }^{1}$
}

\section{RESUMO}

Melissa Mika Kimura Paz

Esta pesquisa pretende analisar se as comunidades tradicionais têm igualdade de acesso aos selos de Indicação Geográfica (IG), que consistem em sinais distintivos que vinculam um produto ou serviço ao seu território de origem, agregando-lhes valores como reputação, notoriedade, cultura e tradição. Os objetivos específicos são apresentar a teoria da igualdade de recursos de Dworkin, o papel da liberdade e ponderar se a Instrução Normativa n. 95 do INPI, que estabelece o procedimento para a obtenção do selo, garante igualdade de acesso às comunidades tradicionais, utilizando, para tanto, a pesquisa bibliográfica e a consulta de dados e da legislação.

Palavras-chave: Indicação geográfica. Comunidades tradicionais. Liberdade. Igualdade de acesso. Dworkin.

AN ANALYSIS OF INSTRUCTION N.95 OF THE INPI IN THE LIGHT OF RONALD DWORKIN'S THEORY OF EQUALITY RESOURCES: geographical indications and traditional communities

\begin{abstract}
This research aims to analyze if traditional communities have equal access to Geographical Indication (GI), which consist of distinctive signs that link a product or service to its territory of origin, adding values such as reputation, notoriety, culture and tradition. The specific objectives are to introduce Dworkin's theory of equality resources, the role of freedom, and consider if Normative Instruction n. 95 of the INPI, which establishes the procedure for obtaining the seal, guarantees equal access to traditional communities, using, for this purpose, bibliographic research and consultation of data and legislation.
\end{abstract}

Keywords: Geographical Indication. Traditional communities. Freedom. Equality of resources. Dworkin.

\section{INTRODUÇÃO}

\footnotetext{
${ }^{1}$ Doutora em Direito pela Universidade Federal de Minas Gerais (UFMG). Professora dos Cursos de Graduação e Mestrado do Centro Universitário do Pará (CESUPA). Desembargadora do Tribunal Regional do Trabalho da $8^{a}$ Região.

2 Mestranda em Direito, Políticas públicas e Desenvolvimento regional pelo Centro Universitário do Pará (CESUPA). Integrante da Comissão de Propriedade Intelectual e Inovação da OAB/PA. Email:melissapaz29@gmail.com.

Rev. de Direito, Inovação, Propriedade Intelectual e Concorrência| e-ISSN: 2526-0014| Goiânia| v. 5 | n. 1 | p. 21-41| 
As indicações geográficas (IG) são sinais distintivos que vinculam um produto ou serviço ao seu território de origem, um selo que agrega valores como reputação, notoriedade, cultura e tradição, que podem ser utilizados como instrumento para o desenvolvimento regional.

As IG estão reguladas por leis e normas que formam o conjunto normativo que rege o instituto no Brasil. Esse conjunto normativo influencia diretamente no acesso ao registro pelos produtores e prestadores de serviço. Neste artigo, será analisado o acesso dos agricultores familiares das comunidades tradicionais à IG, com base na teoria igualitária de Dworkin.

Desse modo, o trabalho dedica-se a compreender de que maneira a teoria da igualdade de recursos de Ronald Dworkin pode ser utilizada para verificar se há desigualdade no acesso ao registro de Indicação Geográfica pelas comunidades tradicionais.

Os objetivos específicos do presente estudo são apresentar a teoria da igualdade de recursos e o papel da liberdade, analisar a Instrução Normativa n. 95 do INPI e, por fim, ponderar se o Estado garante a igualdade de recursos às comunidades tradicionais no que diz respeito à obtenção das indicações geográficas.

O referencial teórico utilizado nesta pesquisa foi o autor Ronald Dworkin e seu livro "A virtude soberana: teoria e prática da igualdade" (2011), no qual apresenta a teoria da igualdade de recursos, que determina que todos devem ser tratados com igual consideração e respeito pelo Estado.

A teoria da igualdade distributiva de Dworkin foi criada para o sistema de livre mercado, adotado pelo Brasil, pois é uma teoria igualitária que aceita diferenças, mas que defende que seja garantida igualdade de recursos, afastando o pensamento de que o sistema de mercado capitalista seria incompatível com uma teoria de igualdade.

A metodologia utilizada foi a pesquisa bibliográfica em livros, periódicos e dissertações sobre o tema proposto, além da consulta à Lei 9. 279/96, à Instrução Normativa n. 95 do INPI e a dados produzidos em sítios oficiais como o Instituto Nacional da Propriedade Industrial.

O trabalho foi dividido em introdução, quatro seções de desenvolvimento, considerações finais e referências. Na seção 2, intitulada "Igualdade de recursos", apresentarse-á a teoria distributiva de Ronald Dworkin, consoante a qual os indivíduos devem ser iguais

Rev. de Direito, Inovação, Propriedade Intelectual e Concorrência | e-ISSN: 2526-0014| Goiânia| v. 5 | n. 1 | p. 21-41| 
em recursos, não se preocupando com a garantir de igualdade em bem-estar. Destacar-se-á o caso hipotético dos imigrantes em uma ilha deserta, o leilão e o teste de cobiça.

Na seção 3, intitulada "Liberdade na teoria da igualdade de recursos", analisar-se-á o papel da liberdade para a teoria igualitária, destacando-se a importância de ambos os conceitos, que são complementares, fundamentados no princípio da abstração, não havendo o absolutismo da liberdade, tampouco o da igualdade.

$\mathrm{Na}$ seção 4, intitulada "Instrução normativa n. 95 do INPI e o instituto da indicação geográfica", será apresentado o procedimento para a concessão do selo da IG pelo INPI, e destacados os benefícios que podem ser gerados em prol do desenvolvimento, especificamente, de territórios da agricultura familiar.

Finalmente, a seção 5, intitulada "Comunidades tradicionais, as indicações geográficas e a teoria da igualdade de recursos", tratará sobre as dificuldades das comunidades tradicionais no processo de registro das IG, analisando se há uma violação à igualdade dessas comunidades para a obtenção do selo.

\section{IGUALDADE DE RECURSOS}

A igualdade que se trata neste trabalho corresponde à igualdade em seu sentido normativo, segundo a qual se empresta relevo ao aspecto de as pessoas deveriam ser iguais ou tratadas da mesma maneira, sendo injusto tratamento diferente.

A igualdade de recursos de Ronald Dworkin distribui ou transfere recursos de modo que nenhuma transferência adicional possa deixar os indivíduos mais iguais em suas parcelas de recursos, distinguindo-se da igualdade de bem-estar, que se preocupa em deixar as pessoas iguais no que estas acreditam que é fundamental em suas vidas. $\mathrm{O}$ autor afasta esse tipo de igualdade argumentando que as pessoas possuem avaliações diferentes do que seria este bemestar (DWORKIN, 2011).

A teoria do liberalismo igualitário de Dworkin possui dois princípios basilares, o princípio do igual cuidado e o da responsabilidade especial. O igual cuidado determina que o governo deve demonstrar a todos os indivíduos o mesmo cuidado; o segundo impõe que este respeite "a responsabilidade e o direito de cada pessoa de fazer de sua própria vida algo de valor.” (KLAUTAU FILHO, 2013, p. 241).

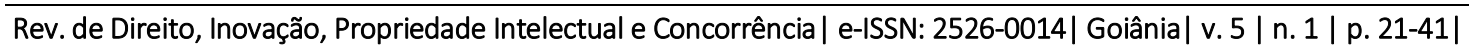


O princípio do igual cuidado impede que a sociedade escolha um sistema que leve a grandes desigualdades. Por outro lado, a análise desses dois princípios não chancelaria um sistema em que todas as riquezas fossem recolhidas e depois distribuídas igualmente, uma vez que as pessoas devem ser responsáveis por suas escolhas de trabalho, lazer, poupança ou investimentos, por exemplo, devendo arcar com os custos dessas escolhas (KLAUTAU FILHO, 2013).

Deve ser ressaltado que o fundamento para a teoria da igualdade de recursos de Dworkin é o princípio abstrato igualitário que determina que as pessoas e o Estado tratem todos os membros da comunidade com igual consideração e respeito. A distribuição igualitária de recursos representa a melhor interpretação desse princípio (DWORKIN, 2011).

A teoria da igualdade de recursos é ideal para ser implementada no sistema de mercado capitalista, que não deve ser considerado incompatível com uma teoria distributiva.

Contudo o mercado econômico, defendido em uma ou ambas as maneiras, veio a ser consagrado, durante o mesmo período, como o inimigo da igualdade, em grande parte porque as formas dos sistemas de mercado econômico criadas e implementadas nos países industriais permitiram e, de fato, incentivaram uma ampla desigualdade quanto à propriedade. Tanto os filósofos políticos quanto os cidadãos comuns definiram a igualdade, portanto, como adversária ou vítima dos valores da eficiência e da liberdade supostamente oferecidos pelo mercado, de modo que a política sensata e moderada consistiria em atingir algum equilíbrio ou intercâmbio entre a igualdade e esses outros valores, seja impondo restrições ao mercado como ambiente econômico, ou substituindo-o, em parte ou totalmente, por outro sistema econômico (DWORKIN, 2011, p. 80/81).

A teoria da igualdade de recursos permite que existam diferenças após a distribuição inicial de recursos. Para explicar como ocorreria a distribuição inicial, Dworkin apresenta uma situação hipotética de distribuição, o caso dos imigrantes em uma ilha desabitada e com muitos recursos, e discute qual seria a melhor maneira para os distribuir entre os imigrantes (DWORKIN, 2011).

O autor sugere que essa divisão ocorra por meio de um leilão ou outro método de mercado em que as pessoas fariam lances pelos recursos físicos da ilha, utilizando conchas como moedas de troca, que seriam o recurso inicial distribuído igualmente entre todos, para que, ao final de uma divisão igualitária, ninguém preferisse ter recebido a parte de outra pessoa (DWORKIN, 2011).

Rev. de Direito, Inovação, Propriedade Intelectual e Concorrência | e-ISSN: 2526-0014| Goiânia| v. 5 | n. 1 | p. 21-41| 
Deverá ser feito o que Dworkin chama de teste de cobiça, que é a verificação, ao final do leilão, de que todos ficaram satisfeitos com a sua parte. Quando ninguém desejar aquilo que é de outra pessoa, a igualdade de recursos foi exitosa, mesmo que nessa distribuição as pessoas tenham diferenças em seu bem-estar (DWORKIN, 2011).

O teste de cobiça não teria êxito com uma divisão simples e mecânica de recursos. Isto porque o leilão pressupõe que as pessoas tiveram a oportunidade de escolher e comprar o que mais gostaram, de acordo com seus planos, projetos e preferências de vida. Tal teste refere-se ao aqui e ao agora. O caso do leilão poderá ser aplicado para a criação de instituições políticas e econômicas na sociedade real em busca da aplicação da igualdade de recursos (DWORKIN, 2011).

$\mathrm{Na}$ igualdade de recursos, porém, as pessoas decidem que tipo de vida procurar munidas de um conjunto de informações sobre o custo real que suas escolhas impõem a outras pessoas e, consequentemente, ao estoque total de recursos que pode ser equitativamente utilizado por elas (DWORKIN, 2011, p. 86).

Dessa forma, a igualdade de recursos determina que os recursos sejam iguais na vida dos indivíduos. O leilão e o teste de cobiça permitem perceber que as pessoas devem entrar no mercado em igualdades de condições, para, então, realizarem suas escolhas de acordo com a vida que desejam levar. Em outras palavras, as pessoas devem arcar com o custo da vida que escolheram, este sendo "avaliado naquilo de que outras pessoas abrem mão para que possam viver como escolheram" (DWORKIN, 2011, p. 92).

A sorte influencia na situação da pessoa, pois pode ser que ela não goste de nenhum item do leilão ou que várias pessoas tenham a mesma preferência que ela. Mas ela não poderá dizer que o tipo de distribuição foi injusto, uma vez que todos receberam a mesma quantidade de recursos iniciais (DWORKIN, 2011).

O leilão realiza apenas uma distribuição inicial dos recursos, que é alterada na medida em que as decisões relacionadas ao comércio, à produção e ao consumo dos indivíduos posteriores ao leilão refletem diretamente na modificação da distribuição. Além disso, os recursos que uma pessoa possui, assim como o bem-estar que estes lhe proporcionam, dependem não só de suas ações individuais, mas das decisões de outras pessoas (DWORKIN, 2011).

A igualdade de recursos não determina que uma redistribuição ocorra após o leilão inicial. Caso a redistribuição ocorresse, alguns tipos de vida seriam impossíveis de serem Rev. de Direito, Inovação, Propriedade Intelectual e Concorrência| e-ISSN: 2526-0014| Goiânia| v. 5 | n. 1 | p. 21-41| 
vividos. Se um indivíduo que resolveu fazer uma aposta ganhasse e, depois, tivesse que dividir seu lucro com aqueles que escolheram seguir por uma vida mais segura sem apostas, as pessoas perderiam o interesse em realizar apostas individuais. E aqueles que desejam uma vida com um imenso sucesso econômico jamais conseguiriam executar seu plano de vida (DWORKIN, 2011).

A igualdade deve existir na oportunidade de fazer a aposta, de modo que, aplicando-se o teste de cobiça, só teriam inveja aqueles que nunca tiveram a oportunidade de realizar uma aposta semelhante (DWORKIN, 2011)."Em linhas gerais, Dworkin (2011) se propõe a estabelecer um modelo sensível à ambição das pessoas e justo na responsabilização pela escolha individual de ações (pautado, assim, na igual consideração e respeito) (...)" (BRITO FILHO; LAMARÃO NETO, 2018).

Por isso, afirma-se que a teoria da igualdade de recursos é compatível com o sistema capitalista e autoriza diferenças, na medida em que permite que aqueles que apostam, ganhem mais dinheiro do que os que não apostam, ou os que perdem as apostas, podendo um indivíduo controlar mais recursos do que outro.

Com relação ao trabalho e aos salários, um produtor de tomates que trabalha muito em seu terreno para ter muito dinheiro, ao fim do ano possui mais recursos do que outras pessoas na comunidade, que passam a desejar seu recurso, mas que não querem levar a vida que o produtor teve para os adquirir. Neste caso, o teste de cobiça não deve ser aplicado para os recursos finais e, sim para verificar a possibilidade de escolha de ocupação, que seria parte de sua parcela de bens, distribuída no leilão inicial (DWORKIN, 2011).

Assim, se todos tiveram a oportunidade de escolher aquela ocupação e apenas o produtor de tomates a escolheu, não há desigualdade na distribuição de bens se ao final do ano este produtor possuir mais recursos que os demais (DWORKIN, 2011).

Devemos, então, aplicar o teste de cobiça diacronicamente: ele requer que ninguém deseje a parcela de ocupação e recursos à disposição de qualquer pessoa no decorrer do tempo, embora alguém possa cobiçar a parcela de outra pessoa em determinado momento. Por conseguinte, violaria a igualdade de recursos se a comunidade redistribuísse a riqueza de Adrian, digamos, ao fim de cada ano. Se todos tivessem talentos iguais (como estamos supondo agora mesmo), o leilão inicial produziria uma simetria constante de recursos, embora os saldos nas contas bancárias se tornassem cada vez mais desiguais com o passar dos anos (DWORKIN, 2011, p. 107).

Rev. de Direito, Inovação, Propriedade Intelectual e Concorrência| e-ISSN: 2526-0014| Goiânia| v. 5 | n. 1 | p. 21-41| 
Podem ser implementados mecanismos de redistribuição, como os programas de tributação, para diminuir as diferenças criadas em decorrência das capacidades. Mas, em geral, as pessoas são diferentes, possuem talentos, preferências e características diferentes, e a igualdade de recursos não estabelece que elas se tornem iguais nesses aspectos. É necessário que elas possuam os mesmos recursos iniciais para que possam executar seu plano de vida de acordo com essa diversidade. Por isso, os recursos não permanecem os mesmos para todos (DWORKIN, 2011).

\section{A LIBERDADE NA TEORIA DA IGUALDADE DE RECURSOS}

A teoria da igualdade de recursos gera reflexo sobre o papel e a limitação da liberdade nesta sociedade, sendo a liberdade correspondente ao conceito de liberdade negativa, de ausência de restrições legais.

A igualdade de recursos é uma igualdade distributiva imediata, na qual a liberdade possui um papel importante, fazendo com que a distribuição não dependa apenas dos resultados mediatos, como o nível de bem estar, e sim, seja decorrente de um processo em que as escolhas das pessoas, suas aspirações e seus projetos refletem no resultado desta distribuição (DWORKIN, 2011).

Se uma sociedade real vai aproximar-se da igualdade de recursos depende, então, da adequação do processo de discussão e escolha que oferece para essa finalidade. É necessário um grau substancial de liberdade para que tal processo seja adequado, pois o verdadeiro preço para outrem de uma pessoa ter algum recurso ou oportunidade só pode ser descoberto quando as aspirações e convicções das pessoas são autênticas e suas opções e decisões bem-adaptadas a essas aspirações e convicções. Nada disso é possível sem ampla liberdade (DWORKIN, 2011, p. 160).

Deve ser observado pelo indivíduo, em uma sociedade de igual consideração, que suas escolhas possuem consequências para os demais indivíduos. Assim, o indivíduo só deve utilizar os recursos que lhe pertencem para executar seu plano de vida, devendo modificar seu plano se este não corresponder à parcela de recursos disponíveis para ele (DWORKIN, 2011).

Ao adotar a teoria da igualdade de recursos como ideal político, a liberdade não deve ser tratada como um ideal político conflitante e mais importante. O Estado, observando o princípio igualitário abstrato, deve tomar decisões que tornem a vida dos indivíduos melhor, devendo demonstrar igual consideração pelas vidas deles. Neste contexto, não há como

Rev. de Direito, Inovação, Propriedade Intelectual e Concorrência| e-ISSN: 2526-0014| Goiânia| v. 5 | n. 1 | p. 21-41| 
defender a supremacia da liberdade sem que se defenda que o governo deve priorizar a melhoria da vida de alguns em detrimento de outros (DWORKIN, 2011).

É equivocado o pensamento de que, em algumas situações, o governo pode negligenciar atos políticos necessários para a aplicação do princípio da igual consideração para que outras metas sejam alcançadas, para justificar, por exemplo, que o objetivo de aumentar a influência e o poder do Estado deve ser buscado, mesmo que não tenha reflexos no aumento da qualidade de vida dos indivíduos (DWORKIN, 2011).

Deve ser ressaltado que a liberdade não é transformada em um simples instrumento da igualdade distributiva. Os dois conceitos são necessários para que a distribuição e o uso dos recursos sejam realizados de forma que todas as pessoas sejam tratadas com igual consideração. São duas virtudes que expressam, em conjunto, o mesmo ideal humanista, existindo as liberdades que são mais importantes para esse processo e aquelas que devem ser limitadas (DWORKIN, 2011).

Segundo Dworkin (2011), o governo não deve limitar essas liberdades essenciais sem que exista uma razão muito forte que justifique tal ato. Dentre essas liberdades essenciais estão a liberdade de consciência, expressão e religião, a liberdade de escolha na vida privada, como seu trabalho, organização familiar, privacidade sexual e tratamentos médicos. Dessa forma, a liberdade não é sinônimo de permissividade, mas um conjunto de direitos vinculados a certas liberdades.

A importância da liberdade deve ser reconhecida. A vida em liberdade possui mais valor, por isso, para a aplicação da teoria igualitária, o governo deve protegê-la. Um conflito entre estes conceitos existiria apenas com a defesa de dois argumentos, que o autor refuta. Primeiro, que a vida de algum grupo apenas melhoraria com a restrição da liberdade de outros e, segundo, que o princípio da igual consideração por tal grupo exigiria que essa restrição acontecesse (DWORKIN, 2011).

Dworkin (2011) analisa uma situação hipotética, na qual se argumenta que, para os pobres terem melhor atendimento médico, a medicina particular não deveria existir, de modo que todos passassem a usar a medicina pública. Neste caso, a igualdade determinaria que os indivíduos recebessem o mesmo tipo de tratamento médico. Para o autor, não é isto que o

Rev. de Direito, Inovação, Propriedade Intelectual e Concorrência | e-ISSN: 2526-0014| Goiânia| v. 5 | n. 1 | p. 21-41| Jan/Jun. 2019 
princípio da igual consideração requer. Não existe, neste caso, um conflito liberdade versus igualdade, mas ideias diferentes sobre o que o princípio requer.

[...] Segundo a igualdade de recursos, os direitos à liberdade que consideramos fundamentais são uma parte ou um aspecto da igualdade distributiva, e estão, portanto, automaticamente protegidos sempre que se alcança a igualdade. A prioridade da liberdade está assegurada, não há custa da igualdade, mas em seu nome. [...] Só argumento que os direitos adequados a uma concepção atraente de liberdade recebem lugar tão fundamental na igualdade de recursos, que não podem surgir conflitos entre esses direitos e tal definição de igualdade distributiva (DWORKIN, 2011, p. 177-178).

A igualdade de recursos necessita de uma distinção entre a pessoa e as circunstâncias dessa pessoa. A pessoa tem características da personalidade que são as suas convicções, aspirações, gostos e preferências. As circunstâncias são os recursos, os talentos e as capacidades que o indivíduo possui (DWORKIN, 2011).

O bem-estar da pessoa depende tanto das características de sua personalidade, quanto das circunstâncias. Já a igualdade de recursos apenas se preocupa com a equiparação das circunstâncias (DWORKIN, 2011).

A liberdade seria submetida a um teste de cobiça da mesma maneira que os recursos materiais, sendo tratada como qualquer outro recurso, se fosse considerada uma circunstância. Com base nisso, a liberdade dos indivíduos dependeria de quais liberdades são mais valorizadas pela sociedade (DWORKIN, 2011).

Todavia, a teoria da igualdade de recursos não poderá depender de tal pensamento, pois há quem não se importe com certas liberdades fundamentais e as pessoas acabariam com diferentes tipos de liberdades, tornando a sociedade difícil de administrar (DWORKIN, 2011).

A liberdade garantida por um Estado não deve depender de decisões particulares dos indivíduos em uma espécie de leilão, mas sim ser anterior a realização do leilão. Um sistema de parâmetros de liberdade é necessário, uma vez que parâmetros diferentes produzem resultados diferentes, mesmo que as preferências e os projetos de vida das pessoas sejam os mesmos (DWORKIN, 2011).

[...] Mas o teste de cobiça pressupõe um sistema de liberdades/restrições e não pode ser usado para produzir um sistema desses, pois qualquer conjunto de estipulações de fundo que viermos a pressupor sobre o que as pessoas terão ou não liberdade de fazer com os recursos que adquirem será atendido por um leilão bem-sucedido com tal pano de fundo. Se o pano de fundo estipular que ninguém pode usar os recursos adquiridos, a não ser de

Rev. de Direito, Inovação, Propriedade Intelectual e Concorrência| e-ISSN: 2526-0014| Goiânia| v. 5 | n. 1 | p. 21-41| 
algumas maneiras enumeradas, o teste de cobiça estará satisfeito: as pessoas farão escolhas tendo em mente essas graves restrições à liberdade e, hipoteticamente, não preferirão nenhum conjunto de recursos que outra pessoa escolher, dadas as mesmas restrições. [...] (DWORKIN, 2011, p. 196).

Assim, se todos possuírem a mesma liberdade ampla para adquirir o que desejam, após o leilão, a distribuição será isenta de cobiça. A igualdade de recursos possui, então, dois estágios: o primeiro é a determinação dos parâmetros e condições nos quais o leilão se realizará, quando são escolhidas as liberdades essenciais para a equidade; o segundo estágio é composto pelo teste de cobiça e o leilão imaginário (DWORKIN, 2011).

Para compreender o conceito de liberdade adotado por Dworkin, faz-se necessária a observância do princípio da abstração, fundamentado na liberdade de escolha, segundo o qual a distribuição ideal de recursos apenas é possível quando os indivíduos podem agir como quiserem dentro de um limite legal. Devem existir restrições apenas para garantir a segurança ou a propriedade de terceiros, ou para corrigir eventuais imperfeições causadas pelo mercado (DWORKIN, 2011).

A igualdade de recursos utiliza a métrica especial dos custos de oportunidades: determina o valor de qualquer recurso transferível que uma pessoa tem como valor ao qual os outros renunciam porque ele o possui. Julga que tais recursos são simetricamente divididos quando o total de recursos transferíveis de cada pessoa tem o mesmo custo de oportunidade agregado medido dessa forma. O leilão imaginário é elaborado para garantir exatamente esse resultado; se o leilão terminar, então os custos agregados das oportunidades, conforme definido por tal leilão, são os mesmos (DWORKIN, 2011 p. 202).

$\mathrm{O}$ verdadeiro custo de oportunidade de um recurso equivale ao preço que outras pessoas pagariam por este em um leilão onde houvesse a maior possibilidade de flexibilização para adaptação dos planos e preferências individuais; os recursos devem ser oferecidos nessa forma abstrata (DWORKIN, 2011).

Esta neutralidade, que determina que os recursos necessários aos indivíduos para realizar seu projeto de vida não podem ser determinados pelo juízo coletivo, não garante a execução de qualquer tipo de vida. Deve ser analisado se é possível satisfazer esse plano, pagando os custos de oportunidades (DWORKIN, 2011).

No mundo real o sistema de liberdades pode ser injusto, a maioria das pessoas de baixa renda sofre, quando o princípio da abstração não é realmente observado e o sistema de

Rev. de Direito, Inovação, Propriedade Intelectual e Concorrência | e-ISSN: 2526-0014| Goiânia| v. 5 | n. 1 | p. 21-41| 
distribuição é inadequado à igualdade de recursos. Essas pessoas possuem um déficit de recursos quando existe uma diferença entre os recursos à que elas tiveram acesso e aquilo que deveriam possuir se o sistema de distribuição fosse realmente equânime e justo (DWORKIN, 2011).

Por outro lado, os indivíduos possuem um déficit de liberdade quando, além do seu déficit de recursos, eles estão em uma situação pior porque o sistema de liberdades e restrições não é o ideal para a igualdade de recursos (DWORKIN, 2011).

Passemos, então, à análise do procedimento para a obtenção de IG à luz dessas considerações

\section{INSTRUÇÃO NORMATIVA N. 95 DO INPI E O INSTITUTO DA INDICAÇÃO GEOGRÁFICA}

As indicações geográficas são ativos intangíveis de titularidade coletiva com prazo indeterminado, reguladas no Brasil pela Lei 9.279/96, que trata dos direitos e obrigações relativos à propriedade industrial (LPI) e, em seu Título IV, artigo 176, apresenta duas modalidades de IG, a indicação de procedência e a denominação de origem.

De acordo com o art. 177 da referida lei, a indicação de procedência (IP) corresponde a um nome geográfico de país, cidade, região ou localidade de seu território conhecido como origem de extração, produção ou fabricação de determinado produto ou de prestação de determinado serviço. Faz-se necessário que o produto ou serviço tenha boa reputação, isto é, seja reconhecido pela qualidade e prestigiado pelos consumidores e notoriedade, sendo conhecido por muitas pessoas (LAGE; WINTER; BARBOSA, 2013).

A denominação de origem (DO), igualmente, é nome geográfico de país, cidade, região ou localidade de seu território que tenha influência direta na qualidade ou características do produto ou serviço. Esta influência pode ser por fatores naturais e humanos, nos termos do art. 178 da Lei 9.279/96. Para que a IG seja concedida nesta modalidade, é preciso que, além da reputação e da notoriedade, comprove-se a influência do meio geográfico na qualidade ou características do produto ou serviço.

O registro da indicação geográfica é concedido pelo Instituto Nacional de Propriedade Industrial (INPI), por meio da competência atribuída pelo parágrafo único do artigo 182 da

Rev. de Direito, Inovação, Propriedade Intelectual e Concorrência| e-ISSN: 2526-0014| Goiânia| v. 5 | n. 1 | p. 21-41| 
LPI, com base na qual editou, em 21/ 08/ 2013, a Instrução Normativa (IN) no 25/2013 para estabelecer as condições gerais para o registro das IG e conferir uma adequada proteção às duas modalidades. Em 2018, a IN no 25/2013 foi revogada pela IN no 95/2018 , ambas observando o mesmo conceito da lei para a IP e a DO.

O INPI concede o registro às entidades representativas da coletividade, principalmente às associações e aos sindicatos, espécies de organizações sociais que possuem um papel fundamental no registro das IG. Assim, os produtores ou prestadores de serviço precisam formar essas organizações, salvo quando apenas um produtor ou pessoa jurídica está legitimado ao uso exclusivo do nome geográfico, art. $5^{\circ}, \S 3^{\circ}$ da IN. 95/18. Para a realização dos pedidos são necessários os requisitos:

Artigo $7^{\circ}$. O pedido de registro de Indicação Geográfica deverá referir-se a um nome geográfico e conterá: I - requerimento de Indicação Geográfica (modelo I); II - Caderno de especificações técnicas [...]; III - Procuração, se for o caso; IV - Comprovante do pagamento da retribuição correspondente; V - Comprovação da legitimidade do requerente [...]; VI - Em se tratando de Indicação de Procedência, documentos que comprovem que o nome geográfico se tornou conhecido como centro de extração, produção ou fabricação do produto ou de prestação do serviço; VII - Em se tratando de Denominação de Origem, documentos que comprovem a influência do meio geográfico nas qualidades ou características do produto ou serviço [...]; VIII - Instrumento oficial que delimita a área geográfica [...]; IX Se for o caso, a representação gráfica ou figurativa da Indicação Geográfica ou de representação de país, cidade, região ou localidade do território [...].

Além disso, para a IP, é necessária a descrição do processo de extração, produção ou fabricação quando se tratar de produto, ou a descrição da prestação, quando se tratar de serviço. Para a DO é necessária a descrição das qualidades ou das características do produto ou serviço que se relacionem com o meio geográfico, relacionados a fatores humanos ou naturais.

O apontamento dos requisitos da legislação que regula o instituto da IG faz-se necessário para compreender a complexidade do processo, devendo-se observar que, para o seu reconhecimento, são indispensáveis uma série de requisitos que necessitam de apoio técnico especializado, de advogados, engenheiros agrônomos e de produção, historiadores para que possa ser realizado o levantamento histórico-cultural, a vinculação do produto ou

3 Em que pese a recente modificação da IN que rege a matéria, as novidades trazidas pela nova IN não alteram a dificuldade de acesso das comunidades tradicionais à indicação geográfica, objeto desta pesquisa.

Rev. de Direito, Inovação, Propriedade Intelectual e Concorrência| e-ISSN: 2526-0014| Goiânia| v. 5 | n. 1 | p. 21-41| 
serviço com o meio geográfico, a definição da área geográfica, a descrição das características específicas do produto ou serviço e outros serviços que serão necessários. A organização dos produtores em grupos para capacitá-los em prol do registro faz-se imprescindível (MATOS; ROVERE, 2017).

Após a reunião de todos esses documentos e depósito no INPI, inicia-se o processo e o exame do registro do pedido, podendo ser solicitados outros documentos e retificações, observados os prazos estipulados em lei. Esse processo poderá durar anos. Todas as custas são de responsabilidade da organização social de produtores ou prestadores de serviço. O pedido de registro para o Cacau de Tomé-açú no estado do Pará, por exemplo, foi depositado em 2014 e apenas em 21/01/2019 foi registrado como uma indicação de procedência, sendo a IG do estado do Pará (INPI, 2018b).

$\mathrm{O}$ valor de retribuições dos serviços prestados pelo INPI $^{4}$ pelo pedido de registro de IP é de $\mathrm{R} \$ 590,00$ e pelo registro de DO, custa $\mathrm{R} \$ 2.135,00$, sendo taxado os atos necessários durante todo o processo, por exemplo, o cumprimento de uma exigência custa $R \$ 120,00$, e recurso de uma decisão, $\mathrm{R} \$ 275,00$, devendo ser ressaltado que existem alguns descontos para certas entidades (INPI, 2014).

Com a concessão do registro, que possui natureza declaratória, o uso da IG torna-se restrito aos produtores ou prestadores de serviços que estão inseridos no território de origem, sendo este o maior requisito para a manutenção do selo. As IG são capazes de influenciar a relação dos produtores ou prestadores entre si e com o mercado, que estrutura a interação social, econômica e política.

As indicações geográficas são capazes de impulsionar o desenvolvimento regional de territórios marginalizados, ou seja, daqueles territórios que não são os principais destinatários das políticas de desenvolvimento, tanto do aspecto social, quanto econômico. Capazes de valorizar os produtos da agricultura familiar de menor escala, por exemplo, especificamente das comunidades tradicionais.

Dessa forma, pode-se afirmar que a IG agrega valores aos produtos ou serviços, representando uma proteção do trabalho, da cultura e do território da região, além de trazer benefícios para a economia local. Os produtos protegidos pela IG estão muito associados ao

4 Consultados no dia 28/03/19 os valores instituídos pela Portaria MDIC nº 39 de 07/03/2014.

Rev. de Direito, Inovação, Propriedade Intelectual e Concorrência| e-ISSN: 2526-0014| Goiânia| v. 5 | n. 1 | p. 21-41| Jan/Jun. 2019 
saber-fazer, relacionados com as formas tradicionais de produção que precisam de uma especificação para competir no mercado.

A diversificação e a diferenciação dos produtos da agricultura familiar são os meios pelos quais este segmento tem-se integrado ao mercado. Assim, iniciativas como as IG precisam ser tomadas para explorar e valorizar esses recursos disponíveis, para que, por meio de tecnologias e da valorização do saber-fazer local, possam superar as dificuldades decorrentes da evolução tecnológica e de consumo (PEREIRA, 2016).

A valorização do território faz com que as pessoas permaneçam em seu local de origem, não apenas os produtores. Outras pessoas também são beneficiadas pela valorização, com a geração direta de empregos, ou indiretamente, com o aumento do turismo e dos valores dos imóveis da região (MASCARENHAS; WILKINSON, 2014).

Esta proteção do produto da agricultura familiar, valorizando o trabalho, a cultura e o território local é capaz de aumentar a qualidade de vida da população local. A melhoria da qualidade de vida e o protagonismo dos recursos naturais, humanos e culturais de determinado território são características de um desenvolvimento endógeno (PEREIRA, 2016).

A mão de obra familiar traz uma formação peculiar para o negócio que reflete economicamente e socialmente.

Diferentes das demais unidades de produção em que as relações de trabalho são baseadas em contratações e salários, na agricultura familiar a mão de obra é oriunda da família e traz ganhos por reduzir custos com a gestão, supervisão e operacionalização da produção, pois não há a necessidade de pagamento de salário, [...] (PEREIRA, 2016, p. 25).

Algumas propriedades familiares possuem condições de gerar renda para o seu auto sustento, inclusive participando de cadeias agroindustriais. Por outro lado, há aquelas que possuem dificuldades de acesso a recursos básicos, como terra e capital. Além disso, os agricultores possuem uma forma de produção, uma estratégia de sobrevivência, interesses e dificuldades diferentes. Assim, as políticas públicas homogêneas voltadas para a agricultura familiar não possuem eficácia em todas as regiões do país (PEREIRA, 2016).

A agricultura familiar é fundamental para a segurança alimentar, a geração de emprego e renda e o desenvolvimento local em bases sustentáveis e equitativas. Ela foi, entretanto, diretamente atingida pelas políticas de

Rev. de Direito, Inovação, Propriedade Intelectual e Concorrência| e-ISSN: 2526-0014| Goiânia| v. 5 | n. 1 | p. 21-41| 
"modernização agrícola" promovidas pela revolução verde, que trataram o espaço rural como se fosse uniforme e acentuaram as diferenças entre os dois modelos agrícolas (patronal e familiar), provocando a concentração e a especulação fundiárias, o êxodo rural e a marginalização da agricultura familiar (SANTILLI, 2009, p.86/7).

Então, na realidade brasileira a agricultura familiar é muito heterogênea; muitos fatores são causas dessa diversidade, com destaque para as peculiaridades de cada região do país, que possuem histórias e formações diferentes, que pode ser observada nas denominações diversas: o colono, o sitiante, o posseiro e o ribeirinho (PEREIRA, 2016).

Assim, fazem parte da agricultura familiar as comunidades tradicionais, que consistem em grupos que são culturalmente diferenciados e que assim se reconhecem, sujeitos de direitos sobre os seus territórios, recursos e tradições. Possuem formações sociais próprias e fazem uso de seu território, de seus recursos naturais e de seus conhecimentos tradicionais para reprodução cultural, social, religiosa, ancestral e econômica (BRASIL, 2007).

O conhecimento tradicional, transmitido de geração em geração, faz parte da organização social dessas comunidades e desempenha um papel fundamental na vida destas. Um papel não apenas econômico, mas também social e cultural. As indicações geográficas podem ser utilizadas como estratégia de valorização destas comunidades. Entretanto, elas possuem dificuldades no acesso ao registro.

A maioria das indicações geográficas pertence à agricultura familiar do Sul/Sudeste do Brasil, que tem mais abertura no mercado, formando cadeias produtivas fortalecidas. Existe uma grande diferença nos números por região, enquanto a região Sul possui 18, o Sudeste 21, a região Norte possui apenas 4 IG. Uma explicação para essa diferença pode ser a falta de conhecimento dos produtores e consumidores, e a ausência do Estado para garantir a proteção dos produtos das comunidades tradicionais por intermédio da IG (INPI, 2018a).

\section{AS COMUNIDADES TRADICIONAIS, AS INDICAÇÕES GEOGRÁFICAS E A TEORIA DA IGUALDADE DE RECURSOS}

Em que pese a indicação geográfica seja, sim, um mecanismo de desenvolvimento que pode ser utilizado para a melhoria da vida dos indivíduos por meio do reconhecimento do saber-fazer de comunidades mais excluídas, faz-se necessário observar que a forma como a IG é regulada no país dificulta o acesso aos benefícios do registro de IG em duas situações.

Rev. de Direito, Inovação, Propriedade Intelectual e Concorrência| e-ISSN: 2526-0014| Goiânia| v. 5 | n. 1 | p. 21-41| 
A primeira dificuldade é que, após o registro da IG, deve ser formada uma rede entre os diversos atores que pertencem àquele território, para que o uso do selo não se restrinja a somente um setor, que será o formado pelos produtores mais capitalizados, evitando que estes sejam os únicos beneficiários. Assim, a cooperação entre os atores deve ser realizada para que os produtores de classe mais baixa consigam acesso ao registro e aos seus benefícios (PEREIRA, 2016).

Para que os indivíduos tenham permissão para incluir no seu produto o selo da IG, este deve atender aos requisitos das normas registradas no INPI no momento da solicitação, como o regulamento de uso, que são as regras que os produtores devem observar para utilizar o selo, estabelecidas pela entidade representativa da coletividade que solicitou o registro (PEREIRA, 2016).

Assim, para os produtores atenderem aos requisitos são necessários investimentos e especializações, havendo custos que dificultam o acesso ao selo. É comum que os produtores não consigam cumprir as normas estabelecidas no regulamento de uso, como é o caso da região do Pampa Gaúcho, o que gera impactos no processo de desenvolvimento regional (PEREIRA, 2016).

A segunda situação envolve a dificuldade de proceder ao pedido junto ao INPI, problema este muito presente na região norte do país, vivido principalmente pelas comunidades tradicionais que possuem uma agricultura familiar marginalizada e de subsistência.

Logo, em que pese existir previsão normativa para todo o Brasil e os produtos das comunidades tradicionais serem considerados aptos a receberem a proteção da IG, poucos são os registros concedidos a essas comunidades. O estado do Pará possui um processo para a sua primeira IG de uma comunidade tradicional, para a proteção do guaraná da Terra Indígena Andirá-Marau em andamento (INPI, 2018a).

A primeira grande dificuldade de acesso das comunidades tradicionais decorre da exclusão social, que possui como consequência a falta de conhecimento e a ausência de recursos financeiros. Estas comunidades locais do território, durante o processo de desenvolvimento da Amazônia, não foram tratadas como atores capazes de contribuir para esse processo.

Rev. de Direito, Inovação, Propriedade Intelectual e Concorrência| e-ISSN: 2526-0014| Goiânia| v. 5 | n. 1 | p. 21-41| Jan/Jun. 2019 
Dos vários preconceitos relativos à cultura do habitante da Amazônia, pelo menos dois estão claramente expressos e são constantes nos planos e nas políticas públicas para a região, no conhecimento comum e nas iniciativas empresariais. O primeiro deles é o de que os índios e os caboclos viveriam em terras excessivamente vastas e as ocupariam em atividades pouco rentáveis para o Estado e de forma incompatível com a economia e a sociedade contemporâneas. O segundo entende os índios, os negros (quilombolas) e os caboclos como detentores de uma cultura pobre, primitiva, tribal e, portanto, inferior, que nada acrescentariam de positivo ao processo de desenvolvimento (LOUREIRO, 2009, p. 106).

Essa exclusão possui consequências que interferem diretamente na dificuldade de acesso às IG. A exclusão social contribuiu para que a agricultura familiar dessas comunidades se consolidasse como apenas de subsistência, em mque o que não é consumido pela família é comercializado para complementar a renda.

Dessa forma, apesar de muitos produtos das comunidades tradicionais serem conhecidos e vinculados ao seu território de origem, essas comunidades não possuem conhecimento sobre a IG e seus benefícios, o que decorre da falta de acesso à educação e à informação.

Aquelas que conhecem o instituto da IG não possuem recursos suficientes para formar organizações sociais, cumprir os requisitos de qualidade do produto, contratar os especialistas para reunir os documentos para realizar o pedido e arcar com as custas do processo.

Analisando este contexto à luz da teoria da igualdade de recursos de Dworkin, tem-se que não é garantida às comunidades tradicionais a liberdade para a execução do seu plano de vida. O Estado não está sendo capaz de garantir a igualdade de recursos, visto que as comunidades não conseguem obter o que está garantido na Lei 9. 279/ 1996 e na IN. 95 do INPI.

A igualdade de recursos determina que todos devem ser tratados com igual consideração, para que possam com a mesma liberdade de escolha e com os recursos iniciais, decidir sobre os recursos importantes para o seu projeto de vida.

A igualdade garantida pela LPI é apenas formal. O Estado precisa criar políticas públicas que garantam a igualdade distributiva entre os cidadãos, observando o princípio da igual importância e responsabilidade por sua escolha.

O primeiro princípio parte da necessidade de que as políticas e leis adotadas pelo governo possam garantir a todos a possibilidade de realização de suas aspirações independentemente de seu histórico econômico, raça, sexo ou deficiência, conferindo, assim, a todos igual importância. O segundo, aduz

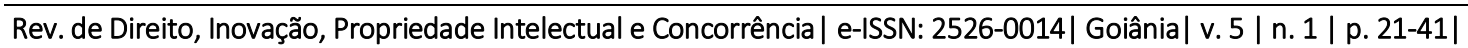


Dessa forma, para que uma distribuição justa e igualitária seja realizada, é necessário que os indivíduos tenham condições de escolha. E a liberdade de escolha das comunidades tradicionais é prejudicada pela exclusão social sofrida por estas.

O princípio da abstração determina que a distribuição igualitária seja fundamentada na liberdade de escolha dentro de um limite legal. No caso das comunidades tradicionais e a IN. 95 do INPI, o sistema de liberdade é injusto e o princípio da abstração não é respeitado.

Pode-se concluir que as comunidades tradicionais possuem um déficit de recursos, pois, caso o sistema de distribuição fosse realmente justo e equânime, elas teriam a possibilidade de requerer a IG ao INPI.

\section{CONSIDERAÇÕES FINAIS}

A teoria da igualdade de recursos de Dworkin determina que os indivíduos devem ser iguais em recursos. Esta teoria representa a melhor interpretação do princípio abstrato igualitário que determina que o Estado deve tratar todos com igual consideração.

Analisando-se o caso hipotético dos imigrantes, com a distribuição por meio do leilão e com a posterior realização do teste de cobiça, percebe-se que o recurso inicial, no caso as conchas, devem ser distribuídos igualmente entre todos para que ao final da distribuição ninguém deseje a parte de outra pessoa.As pessoas devem ter a oportunidade de escolher o que mais gostaram de acordo com seus planos, projetos e preferências de vida.

Dessa forma, a liberdade possui um papel muito importante para a igualdade. Em conjunto, as duas buscam o mesmo ideal humanista do igual respeito e consideração. Para a igualdade de recursos, as liberdades essenciais para a equidade devem ser garantidas antes da realização do leilão e do teste de cobiça.

As indicações geográficas são reguladas pela Lei 9. 279/96 e pela IN. 95 do INPI, que apresentam uma série de requisitos para a obtenção do registro. As IG podem contribuir para o desenvolvimento de regiões marginalizadas, no aspecto social e econômico, ao valorizar o trabalho, a cultura e o território.

Rev. de Direito, Inovação, Propriedade Intelectual e Concorrência | e-ISSN: 2526-0014| Goiânia| v. 5 | n. 1 | p. 21-41| 
Os agricultores familiares das comunidades tradicionais, em especial aqueles de baixa renda, possuem dificuldades para acessar o mercado. A indicação geográfica seria uma estratégia para esse acesso, na medida em que diferencia o produto, facilitando os canais de comercialização.

As comunidades tradicionais são grupos culturalmente diferenciados que, em sua maioria, não participaram do processo de desenvolvimento implementado na Amazônia, o que resultou em sua exclusão social.

Apesar de a IG poder ser utilizada para a valorização dessas comunidades tradicionais, contribuindo para o aumento de sua qualidade de vida, estas possuem muitas dificuldades de obter o registro, por dois motivos principais: a falta de conhecimento e a falta de recursos financeiros, consequências da marginalização que sofrem.

A forma como a IG é regulada no Brasil dificulta o acesso das comunidades tradicionais. De acordo com a teoria da igualdade de Dworkin, há uma violação da igualdade de recursos, na medida em que a liberdade das comunidades, de escolherem os recursos necessário para a execução de seu plano de vida, não é assegurada.

Portanto, pela análise da teoria da igualdade de recursos de Ronald Dworkin verifica que há uma desigualdade no acesso ao registro de Indicação Geográfica pelas comunidades tradicionais, o que impossibilita o desenvolvimento dessas comunidades por meio da melhoria de sua qualidade de vida.

\section{REFERÊNCIAS}

BRASIL. Decreto n. 6.040, de 7 de FEVEREIRO de 2007. Política Nacional de Desenvolvimento Sustentável dos Povos e Comunidades Tradicionais. Disponível em: http://www.planalto.gov.br/ccivil_03/_Ato2007-2010/2007/Decreto/D6040.htm Acesso em: 04/12/2018.

BRASIL. Instrução Normativa 25, de 21 de AGOSTO de 2013. Registro das Indicações Geográficas. Disponível em: <http://www.inpi.gov.br/legislacao1/in_25_21_de_agosto_de_2013.pdf. Acesso em 01/11/2018.

BRASIL. Instrução Normativa 95, de 28 de DEZEMBRO de 2018. Registro das Indicações Geográficas. Disponível em: <www.inpi.gov.br/menu-servicos/indicacaogeografica/arquivos/IN952018.pdf>. Acesso em 28/03/2019.

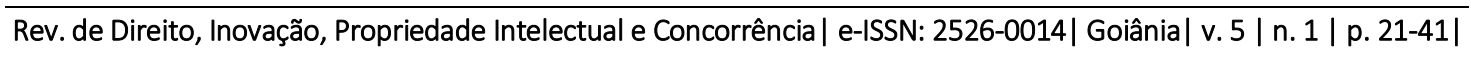


BRASIL. Lei 9.279, de 14 de MAIO de 1996. Lei da propriedade industrial. Disponível em: <http://www.planalto.gov.br/ccivil_03/leis/19279.htm Acesso em 01/11/2018.

BRITO FILHO, José Cláudio; LAMARÃO NETO, Homero. Igual consideração e a incidência das variáveis políticas. In: BRITO FILHO, José Claúdio. Direitos Sociais e liberalismo igualitário: proposta de realização de direitos fundamentais a partir de uma concepção de justiça. Rio de Janeiro: Lumen Juris, 2018.

DWORKIN, Ronald. A virtude soberana: teoria e prática da igualdade. 2 ed. Trad. Jussara Simões, rev. Cícero Araújo e Luiz Moreira. São Paulo: Martins Fontes, 2011.

INPI. Indicações Geográficas, 2018. Disponível em: <http://www.inpi.gov.br/menuservicos/indicacao-geografica/pedidos-de-indicacao-geografica-no-brasil $>$.

Acesso em: 27/07/2018a.

INPI. Indicações Geográficas: Seção IV. Revista da Propriedade Industrial, n. 2495, out, 2018b. Disponível em: http: <//revistas.inpi.gov.br/rpi/ Acesso em: 05/11/2018.

INPI. Tabela de retribuições dos serviços prestados pelo INPI. 2014. Disponível em: http://www.inpi.gov.br/menu-servicos/indicacao-geografica/arquivos/tabela-de-retribuicaode-servicos-de-indicacoes-geograficas-inpi-20170606.pdf. Acesso em: 04/12/2018.

KLAUTAU FILHO, Paulo. T. D. Ronald Dworkin: justiça, direito e unidade de valor. In: DIAS, Jean C; SIMÕES, Sandro A. S. Direito, políticas públicas e desenvolvimento. Rio de Janeiro: forense; São Paulo: Método; Belém: CESUPA, 2013.

LAGE, Celso L. S; WINTER, Eduardo; BARBOSA, Pattrícia M. S. As diversas faces da propriedade intelectual. Rio de Janeiro: UERJ, 2013.

LOUREIRO, Violeta Refkalefsky. A Amazônia no século XXI: novas formas de desenvolvimento. São Paulo: Empório do Livro, 2009.

MASCARENHAS, Gilberto; WILKINSON, John. Indicações geográficas em países em desenvolvimento: Potencialidades e desafios. Revista de Política Agrícola, n. 2, p. 103/115. Abr/jun, 2014.

MATOS, Ligia Aparecida Inhan; ROVERE, Renata Lèbre La. As diferentes interpretações dos conceitos de indicações geográficas por instituições brasileiras. Revista Desenvolvimento Regional em debate, v. 7, n.1, p. 4/24, mai, 2017.

NOBRE, Simone Cruz. Igualdade de recursos. In: DIAS, Jean Carlos (org). Pensamento Jurídico Contemporâneo. São Paulo: Método, 2015.

PEREIRA, M. E. B. G. Coordenação na agricultura familiar e desenvolvimento territorial: o caso das indicações geográficas para o café, 2016. Dissertação (Mestrado em

Rev. de Direito, Inovação, Propriedade Intelectual e Concorrência| e-ISSN: 2526-0014| Goiânia| v. 5 | n. 1 | p. 21-41| Jan/Jun. 2019 
agronegócio e desenvolvimento) - Faculdade de Ciências e Engenharia, Universidade Estadual Paulista, Tupã.

SANTILLI, Juliana. Agrobiodiversidade e direitos dos agricultores. São Paulo: Peirópolis, 2009. 